Nota

\title{
Aclimatização de mudas de helicônia em ambiente protegido em função do tipo de recipiente e do volume do substrato ${ }^{(1)}$
}

\author{
ELIANA. L. J. ROCHA ${ }^{(2)}$; BENITO. M. DE AZEVEDO(3); ALBANISE. B. MARINHO(4); ANA. C. P. P. DE CARVALHO(5); \\ DENISE. V. VASCONCELOS ${ }^{(6)}$; THALES V. DE A. VIANA(7)
}

\begin{abstract}
RESUMO
O presente trabalho teve como objetivo avaliar o efeito de diferentes volumes de substrato e tipos de recipiente na aclimatização de mudas micropropagadas de helicônia (Heliconia lingulata) em ambiente protegido, com irrigação por microaspersão. A pesquisa foi conduzida na Embrapa Agroindústria Tropical, situada no município de Fortaleza - CE (344' S e 38³3' W), durante o período de fevereiro a abril de 2006. O delineamento empregado foi o de blocos casualizados, com quatro tratamentos e cinco repetições. Foram avaliados quatro volumes e tipos de recipientes: copo pequeno $\left(100 \mathrm{~cm}^{3}\right)$; tubete pequeno $\left(180 \mathrm{~cm}^{3}\right)$; tubete grande $\left(300 \mathrm{~cm}^{3}\right)$ e copo grande $\left(400 \mathrm{~cm}^{3}\right)$. As mudas foram cultivadas com substrato a base de pó-de-coco seco+húmus+solo e irrigadas com lâmina de 3 mm por dia parceladas duas vezes por dia. As variáveis agronômicas avaliadas no experimento foram: altura da planta, número de folhas e diâmetro do caule. Os resultados evidenciaram que os volumes do recipiente influenciaram o crescimento das mudas micropropagadas de helicônia; o tubete grande de $300 \mathrm{~cm}^{3}$ e o copo grande de $400 \mathrm{~cm}^{3}$ proporcionaram o maior diâmetro e o maior número de folhas emitidas, e a maior altura de planta foi obtida para o tubete grande $\left(300 \mathrm{~cm}^{3}\right)$, enfatizando ser este o melhor recipiente.
\end{abstract}

Palavras-chave: Heliconia lingulata, micropropagação, pó-de-coco, húmus, recipiente.

\section{ABSTRACT}

Acclimatization of Heliconia lingulata in function of the types of containers and substrate volume

The objective of this work was to evaluate the effect of substrate volume and types of containers in heliconia (Heliconia lingulata) acclimatization when cultivated in green houses, under micro irrigation. The experiment was carried out in the EMBRAPA Tropical Agroindustry Research Station located in Fortaleza, Ceará, Brazil ( $3^{\circ} 44^{\prime}$ S e $38^{\circ} 33^{\prime}$ W), during the period of February to April 2006. The experiment design used was randomized blocks with four treatments and four replications. Four different volumes and four types of containers were evaluated: small cup $\left(100 \mathrm{~cm}^{3}\right)$; small tube $\left(180 \mathrm{~cm}^{3}\right)$; large tube $\left(300 \mathrm{~cm}^{3}\right)$ and large cup $\left(400 \mathrm{~cm}^{3}\right)$. The seedlings were cultivated in media composed by dry coconut powder, organic fertilizer and soil, and were irrigated with depth of $3 \mathrm{~mm}^{\mathrm{may}} \mathrm{e}^{-1}$, divided into two times per day. The agronomic variables evaluated in the experiment were: height of the plant, number of leaves and stem diameter. The results evidenced that the volume of the container influenced the growth of heliconia. The large tube $\left(300 \mathrm{~cm}^{3}\right)$ and large cup $\left(400 \mathrm{~cm}^{3}\right)$ presented higher height, larger (diameters) stem diameter and higher number of leaves.

Keywords: Heliconia lingulata, micropropagation, dry coconut powder, container.

\section{INTRODUÇÃO}

O mercado mundial de flores tropicais tem apresentado crescimento potencial. As exportações brasileiras de flores e plantas cresceram mais de $124 \%$ entre 2001 e 2006 , mantendo crescimento real de pelo menos $10 \%$ por ano (JUNQUEIRA e PEETZ, 2007). As helicônias são plantas ornamentais que, com sua beleza e exotismo, promovem verdadeiras esculturas, lembrando, em sua forma, pirâmides, bicos de aves, cascatas de flores, pinhais, ou cachos de banana.

A aclimatização é a etapa na qual a planta é transferida do laboratório (in vitro) para casa de vegetação ou mesmo, para o campo. A transferência de ambiente totalmente controlado, asséptico, rico em nutrientes e com elevada umidade, para um ambiente não controlado, séptico e com baixa umidade, tem levado a perda de plantas, baixa taxa de crescimento e período prolongado de aclimatização (LAKSO et al., 1986). Portanto, a aclimatização é uma etapa crítica e representa, em muitos casos, o principal percalço na micropropagação de muitas espécies.

Os recipientes são fundamentais à aclimatização, pois proporcionam um melhor aproveitamento do espaço físico, facilitam os tratos culturais, protegem as raízes de danos mecânicos, permitem economia de substrato e ainda maximizam a sobrevivência no campo. A definição do tamanho do recipiente para produção da muda é um importante aspecto, pois influencia diversas características da muda e pode impactar o percentual de sobrevivência no campo e a

\footnotetext{
(1)Parte da Dissertação de Mestrado da primeira autora, financiada pela CAPES. Recebido para publicação em 28/04/2008 e aceito em 21/07/2009

${ }^{(2)}$ Mestre em Irrigação e Drenagem (In memoriam)

${ }^{(3)}$ Professor Adjunto, Departamento de Engenharia Agrícola, Universidade Federal do Ceará/UFC, benitoazevedo@hotmail.com

${ }^{(4)}$ Engenheira Agrícola, Doutora, Pesquisadora CNPq/FUNCAP, albanisebm@gmail.com

${ }^{(5)}$ Doutora, Embrapa Agroindústria Tropical, C. Postal 3761,60511-110 Fortaleza-CE,cristina@enpat.embrapa.br

${ }^{(6)}$ Engenheira Agrônoma, Mestre - Universidade Federal do Ceará/UFC, denisevasconcelos@hotmail.com

(7)Professor Adjunto, Departamento de Engenharia Agrícola, Universidade Federal do Ceará/UFC, thales@ufc.br
} 
produtividade da cultura. A forma e o tamanho desse recipiente exercem marcada influência sobre o crescimento das raízes e da parte aérea da planta. A altura, a presença de ranhuras e a forma do recipiente também são fundamentais para a correta formação da muda (SOUZA, 1995).

Segundo LESKOVAR (1998), variando-se o tamanho do recipiente, altera-se o volume de enraizamento das plantas, o qual afeta o crescimento da parte aérea, sendo observada uma relação positiva entre a quantidade de matéria seca do sistema radicular e da parte aérea. Assim, quanto menor for o espaço disponível às raízes, mais difícil será o suprimento de fatores de produção que garantam o crescimento otimizado e o desenvolvimento normal da muda (MENEZES JÚNIOR et al., 2000).

$\mathrm{Na}$ produção de mudas, podem-se encontrar, dependendo do modelo, diferentes tipos de bandejas, variando o volume de substrato disponível na célula. O volume de substrato disponível para o desenvolvimento radicular pode influenciar o desenvolvimento das mudas. A restrição radicular pode afetar o crescimento, a fotossíntese, o teor de clorofila nas folhas, a absorção de nutrientes e água, a respiração, o florescimento, bem como a produção (NESMITH e DUVAL, 1998). Maior massa de raízes em recipientes pequenos contribui para a redução do espaço poroso e maior competição por oxigênio. As mudas com sistema radicular restringido, quando transplantadas para o campo, são frequentemente incapazes de compensar a evapotranspiração, mesmo se bem irrigadas após o transplante (PEREIRA e MARTINEZ, 1999).

Os recipientes de maior volume proporcionam a melhor arquitetura do sistema radicular (PARVIAINEN, 1981), o maior volume de raízes, que melhora a absorção de nutrientes, e a obtenção de mudas mais vigorosas e de melhor qualidade (BEZERRA, 2003). Os recipientes de menor volume reduzem o crescimento e vigor das mudas, e ainda restringem o desenvolvimento do sistema radicular da planta (BEZERRA, 2003).

A escolha dos recipientes é um dos principais problemas técnicos que muitos produtores têm enfrentado durante a aclimatização de plantas micropropagadas. O apropriado dimensionamento de volume, altura e diâmetro do recipiente depende do ritmo de crescimento das plantas, o qual é função da espécie e das condições de clima e substrato. A restrição do crescimento do sistema radicular, proporcionada pelo volume do recipiente, pode promover o desequilíbrio na razão entre raízes e parte aérea, alterando as respostas fisiológicas da planta (REIS et al., 1989) e repercutindo na qualidade da muda.

Pesquisas têm comprovado, de uma maneira geral, que as mudas de melhor qualidade são obtidas a partir de recipientes de maior volume. SEABRA JÚNIOR et al. (2004), estudando o efeito do volume de substrato na produção de mudas de pepino japonês sob ambiente protegido, verificaram que houve um acréscimo na produção comercial de $25 \%$ quando se utilizaram mudas produzidas em volume maior de substrato. CARDOSO e COSTA (1999) e BARROS (1997), ao estudarem o comportamento de diferentes recipientes na produção de mudas de bulbos de cebola e tomateiro, concluíram que quanto maior o volume do recipiente empregado, maior foi o peso total, o peso da matéria seca da parte aérea e, também, maior foi a área foliar das plântulas. Resultados semelhantes foram obtidos por QUEIROZ e MALÉM JÚNIOR (2001), em mudas de açaí, SOUZA et al. (2001), em mudas de cagaiteira e OLIVEIRA et al. (1993), em mudas de maracujazeiro.

Para SHEPHERD (1986), as más formações causadas nas raízes pelos recipientes na fase de mudas podem provocar problemas nas plantas adultas, anos depois. Entretanto, nessa fase de campo, há carência de trabalhos sobre a influência dos recipientes e substratos usados na produção de mudas. Assim, o objetivo deste trabalho foi avaliar o efeito de diferentes recipientes e volumes de substrato no desenvolvimento de mudas micropropagadas de helicônias, cultivadas em condições de aclimatização.

\section{MATERIAL E MÉTODOS}

O presente trabalho foi conduzido em um túnel alto de cultivo forçado pertencente à Embrapa Agroindústria Tropical, no período de fevereiro a abril de 2006. A área está situada no município de Fortaleza, Ceará, com as coordenadas geográficas correspondentes a $3^{\circ} 44^{\prime}$ de latitude sul, 38 $33^{\prime}$ de longitude oeste e 19,5 m de altitude acima do nível do mar. De acordo com a classificação climática de Köppen, o clima da região é do tipo Aw', caracterizado como clima tropical chuvoso, de savana tropical, com a época mais seca no inverno e máximo de chuvas no outono.

O túnel alto de cultivo forçado, de formato semicircular e orientação leste-oeste, foi instalado com as dimensões de $45 \mathrm{~m}$ de comprimento, $5 \mathrm{~m}$ de largura e $2 \mathrm{~m}$ de altura, comportando aproximadamente uma área de $225 \mathrm{~m}^{2}$ e um volume de 357 $\mathrm{m}^{3}$, coberto por uma tela de sombreamento para reduzir $50 \%$ da luminosidade e com plástico transparente para proteção das chuvas.

O sistema de irrigação empregado foi do tipo microaspersão suspenso, sendo constituído por um conjunto motobomba, uma linha principal, uma linha de derivação e uma linha lateral de $10 \mathrm{~m}$, com emissores espaçados de $2,4 \mathrm{~m}$ e a uma altura de $0,5 \mathrm{~m}$ das bandejas. Os microaspersores foram do tipo Tietze nebulizador, com bocal violeta em posição invertida e vazão de $43 \mathrm{~L} \mathrm{~h}^{-1}$, na pressão de $300 \mathrm{kPa}$. Colocou-se, na extremidade de cada microaspersor, um cordão esticado até a grade de suporte, com o objetivo de evitar acúmulo de água em algum recipiente ocasionado pelas gotas provenientes dos emissores durante a irrigação.

As mudas de helicônias (Heliconia lingulata) utilizadas neste experimento foram obtidas por meio do processo de micropropagação, realizado no Laboratório de Cultura de Tecidos e Genética Vegetal da Embrapa Agroindústria Tropical. Na ocasião do plantio, as mudas apresentavam-se completamente enraizadas e com alturas variando de 2,6 a 3,5 $\mathrm{cm}$.

As plantas provenientes do material in vitro foram retiradas dos frascos e suas raízes foram lavadas em água corrente para a retirada do excesso do meio de cultura. Após a lavagem, as mudas foram colocadas em bandejas e suas raízes, podadas com o auxílio de uma tesoura, com o objetivo de uniformizar 
o material, facilitar o plantio e estimular o desenvolvimento de um sistema radicular mais funcional.

O substrato utilizado foi formado pela combinação póde-coco seco, húmus de minhoca e solo $(\mathrm{PCS}+\mathrm{H}+\mathrm{S})$, na proporção $1: 1: 2$. Após a preparação do substrato, foi feito o procedimento de autoclavagem, para eliminação dos possíveis patógenos. Após este processo, o substrato ficou em repouso por três dias e a partir daí, procedeu-se ao enchimento dos recipientes e transplante das mudas.

O completo umedecimento do substrato e o aumento da umidade relativa do ambiente, momentos antes da transferência das mudas para os recipientes, foram obtidos por meio de irrigação, proporcionando assim um ambiente favorável ao estabelecimento das mudas. Com os recipientes em seus devidos lugares, as mudas foram acondicionadas e levadas em bandejas até o ambiente de cultivo, iniciando a etapa de plantio. O transplante das mudas para os respectivos recipientes com substrato foi realizado no dia 3 de fevereiro de 2006, quando essas alcançaram altura do caule de aproximadamente $5,0 \mathrm{~cm}$. As plantas foram irrigadas diariamente, com uma lâmina de $3 \mathrm{~mm}$, parcelada em duas aplicações: uma lâmina de 1,5 mm pela manhã, às $9 \mathrm{~h}$ e a outra, também de $1,5 \mathrm{~mm}$, no período da tarde, às $16 \mathrm{~h}$.

O delineamento experimental utilizado foi o de cinco blocos casualizados e quatro tratamentos. Cada parcela foi composta por cinco plantas úteis, totalizando 25 plantas por tratamento. Os tratamentos foram constituídos por quatro recipientes com formas e volumes diferentes: copo pequeno (CP) com volume de $100 \mathrm{~cm}^{3}$ e altura de $5,5 \mathrm{~cm}$, tubete pequeno (TP) com volume de $180 \mathrm{~cm}^{3}$ e altura de $13 \mathrm{~cm}$, copo grande (CG) com volume de $400 \mathrm{~cm}^{3}$ e altura de $10 \mathrm{~cm}$, e tubete grande (TG) com volume de $300 \mathrm{~cm}^{3}$ e altura de $19 \mathrm{~cm}$.

As variáveis agronômicas analisadas foram: o número de folhas (NF), a altura do caule (AC) e o diâmetro do caule (DC). O número de folhas foi contado visualmente em toda a extensão da planta. Todas as folhas foram consideradas na contagem, exceto aquelas totalmente secas. A altura do caule foi medida com uso de um escalímetro graduado em centímetros, subdividido em milímetros, a partir da base até a abertura das folhas. $\mathrm{O}$ diâmetro do caule foi mensurado com o auxílio de um paquímetro digital, graduado em centímetros, considerando a base como padrão de contagem.

Os dados foram coletados em três ocasiões distintas. A primeira, em 07 de março (30 DAT); a segunda, em 04 de abril (60 DAT) e a terceira, em 19 de abril (75 DAT). A primeira coleta de dados, realizada no dia 02 de fevereiro (início dos experimentos), foi considerada somente como ponto inicial, ou seja, os valores coletados não sofreram nenhuma influência dos tratamentos.

Como os tratamentos utilizados diferiram qualitativamente, graças aos diversos formatos e materiais de constituição dos recipientes empregados, os dados foram submetidos à análise de variância. Quando os valores obtidos para o teste F foram significativos, as médias foram comparadas pelo teste de Tukey em nível de 5\% de probabilidade de erro, com o auxílio dos aplicativos Microsoft Office Excel (2003) e SISVAR versão 4.6 (FERREIRA, 2003).

\section{RESULTADOS E DISCUSSÃO}

Os resultados das análises de variância para o número de folhas (NF), altura caule (AC) e diâmetro do caule (DC), aos 75 dias após o transplante (DAT), estão apresentadas na tabela 1. Pode-se observar que o emprego de diferentes volumes de substrato influenciou

Tabela 1. Análise de variância com níveis de significância do número de folhas (NF), altura do caule (AC) e diâmetro do caule (DC) de mudas de helicônia (Heliconia lingulata), em função dos volumes de substrato, aos 75 DAT após a aclimatização, Embrapa Agroindústria Tropical, Fortaleza-CE, 2006

Table 1. Analysis of variance with significance levels of the number of leaves, plant height and stem diameter of young Heliconia lingulata, as a function of substrate volume, 75 days after acclimatization, Embrapa Tropical Agro-industry, Fortaleza-CE, 2006

\begin{tabular}{|c|c|c|c|c|}
\hline Variável & FV & GL & SQ & QM \\
\hline \multirow{3}{*}{$\mathrm{NF}$} & Bloco & 4 & 0,545 & $0,136^{\mathrm{ns}}$ \\
\hline & Tratamento & 3 & 6,424 & $2,14_{1}^{*}$ \\
\hline & Resíduo & 12 & 1,431 & 0,119 \\
\hline \multirow{3}{*}{$\mathrm{AC}$} & Bloco & 4 & 4,329 & $1,082^{\mathrm{ns}}$ \\
\hline & Tratamento & 3 & 63,716 & $21,23 \delta^{*-}$ \\
\hline & Resíduo & 12 & 10,490 & 0,874 \\
\hline \multirow{3}{*}{ DC } & Bloco & 4 & 13,194 & $3,298^{\mathrm{ns}}$ \\
\hline & Tratamento & 3 & 94,885 & $\left.31,62 \delta^{*}\right]$ \\
\hline & Resíduo & 12 & 26,175 & 2,181 \\
\hline
\end{tabular}

(ns) não significativo; * significativo pelo teste $\mathrm{F}(\mathrm{p}<0,05)$. 
$\mathrm{Na}$ fase inicial da cultura (30 e 60 DAT), não se verificou efeito significativo dos tratamentos, possivelmente por causa do menor estádio de desenvolvimento das mudas e, consequentemente, da menor área ocupada pelas raízes.

Entre os recipientes utilizados, verificou-se que o tubete grande $\left(300 \mathrm{~cm}^{3}\right)$ e o copo grande $\left(400 \mathrm{~cm}^{3}\right)$ não diferiram estatisticamente entre si e proporcionaram as maiores médias de diâmetro de caule, altura do caule e número de folhas (tabela 2), ou seja, os melhores resultados ocorreram com os recipientes de altura e volume maiores. Isso pode ter ocorrido em decorrência de características intrínsecas destes recipientes, e pelo fato de eles oferecerem maior disponibilidade de substrato para a exploração do sistema radicular, o que, possivelmente, melhorou o desenvolvimento das mudas.

Tabela 2. Médias e coeficientes de variação para número de folhas (NF), altura do caule (AC) e diâmetro do caule (DC) de mudas de helicônia (Heliconia lingulata), aos 75 DAT após o início da fase de aclimatização, de acordo com os volumes de recipientes utilizados, Embrapa Agroindústria Tropical, Fortaleza-CE, 2006

Table 2. Means and coefficients of variation of the number of leaves, plant height and stem diameter of young Heliconia lingulata, 75 days after acclimatization, as a function of volume of the container used, Embrapa Tropical Agro-industry, Fortaleza-CE, 2006

\begin{tabular}{|c|c|c|c|}
\hline \multirow{2}{*}{ Tipo e volume de recipiente } & \multicolumn{3}{|c|}{ Variável } \\
\hline & $\mathrm{DC}(\mathrm{mm})$ & $\mathrm{AC}(\mathrm{cm})$ & $\mathrm{NF}$ \\
\hline TG $\left(300 \mathrm{~cm}^{3}\right)$ & $13,2 \mathrm{a}$ & $11,9 \mathrm{a}$ & $3,9 \mathrm{a}$ \\
\hline $\mathrm{CG}\left(400 \mathrm{~cm}^{3}\right)$ & $12,7 \mathrm{a}$ & $9,2 \mathrm{~b}$ & $3,9 \mathrm{a}$ \\
\hline $\mathrm{TP}\left(180 \mathrm{~cm}^{3}\right)$ & $9,8 \mathrm{~b}$ & $8,9 \mathrm{~b}$ & $3,1 \mathrm{~b}$ \\
\hline $\mathrm{CP}\left(100 \mathrm{~cm}^{3}\right)$ & $7,8 \mathrm{~b}$ & $6,9 \mathrm{c}$ & $2,6 \mathrm{~b}$ \\
\hline CV (\%) & 13,6 & 10,1 & 10,2 \\
\hline
\end{tabular}

Médias seguidas de mesma letra minúscula nas colunas não diferem entre si pelo teste de Tukey $(\mathrm{p}<0,05)$.

A altura do caule variou em função dos volumes dos recipientes, verificando-se que o tubete grande $\left(300 \mathrm{~cm}^{3}\right)$ proporcionou maior altura média, de 11,9 $\mathrm{cm}$. Maior volume de substrato, além de disponibilizar maior quantidade de água e nutrientes, propicia maior espaço para a expansão do sistema radicular e consequente aumento da absorção de nutrientes, resultando em maior crescimento das plantas. Estes resultados estão em concordância com OLIVEIRA et al. (2008), os quais verificaram que recipiente de maior volume tem grande influência no desenvolvimento de mudas de bananeiras, por proporcionar um bom desenvolvimento do sistema radicular.

Os recipientes de menor capacidade volumétrica, copo pequeno $\left(100 \mathrm{~cm}^{3}\right)$ e tubete pequeno $\left(180 \mathrm{~cm}^{3}\right)$, não diferenciaram entre si e proporcionaram crescimento inferior, com menores valores de diâmetro de caule, número de folhas e altura de caule, o que evidencia a limitação causada pelo volume e a altura do recipiente.

BOMFIM et al. (2007), avaliando o efeito de diferentes volumes de substrato em mudas micropropagadas de abacaxizeiro ornamental (Ananas comosus var. erectifolius), verificaram que os tubetes de $180 \mathrm{~cm}^{3}$ proporcionaram maior desenvolvimento das mudas. Resultados semelhantes foram obtidos por SOUZA et al. (2001), avaliando o efeito de diferentes tipos e volumes de substrato na emergência das plantas de cagaiteira, por BARROS (1997), avaliando a produção de mudas de tomate e pepino e por OLIVEIRA et al. (1993), avaliando a produção de mudas maracujazeiro em diferentes recipientes. Os autores observaram que o melhor desenvolvimento das plantas ocorreu quando foram utilizadas bandejas com células de maior volume, independentemente do substrato utilizado. Estes autores acreditam que isto se deve, provavelmente, ao maior volume que está envolvendo o sistema radicular, propiciando condições mais satisfatórias para o desenvolvimento das mudas.

QUEIROZ e MALÉM JÚNIOR (2001), testando três tamanhos diferentes de recipientes na produção de mudas de açaí, verificaram que os recipientes de tamanho médio e grande proporcionam o melhor desenvolvimento de mudas; observaram, no entanto que o recipiente de tamanho médio utiliza menos substrato e horas de trabalho e propicia muda com o mesmo desenvolvimento que as obtidas com os de tamanho grande. Concluíram que o recipiente de tamanho médio é o tipo de recipiente mais adequado para a produção de mudas de açaí.

\section{CONCLUSÕES}

Os recipientes com maior capacidade volumétrica, no caso tubete grande $\left(300 \mathrm{~cm}^{3}\right)$ e copo grande $\left(400 \mathrm{~cm}^{3}\right)$, foram os que proporcionaram mudas mais vigorosas em termos de diâmetro de caule e número de folhas emitidas. A altura do caule apresentou maior desenvolvimento quando aclimatizada em tubete grande. Dessa forma, recomenda-se a aclimatização de mudas de helicônia em tubete grande, visto que, em relação ao copo grande, irá ocupar menor espaço do ambiente protegido e necessitar de menor quantidade de substrato e demais insumos. 


\section{REFERÊNCIAS}

BARROS, S. B. M. Avaliação de diferentes recipientes na produção de mudas de tomate (Lycopersicon esculentum Mill.) e pepino (Cucumis sativus L.). Piracicaba: Escola Superior de Agricultura Luiz de Queiroz, Universidade de São Paulo, 1997. 70p. Dissertação (Mestrado).

BEZERRA, F. C. Produção de mudas de hortaliças em ambiente protegido. Fortaleza: Embrapa Agroindústria Tropical, 2003. 22 p. (Documentos, 72).

BOMFIM, G. V. do, CARVALHO, A. C. P. P. de, BEZERRA, F. C., AZEVEDO, B. M. de, VIANA, T. V. de A., OLIVEIRA, K. M. A. S. de. Aclimatização de mudas micropropagadas de abacaxizeiro ornamental em diferentes volumes de substrato. Revista Brasileira de Horticultura Ornamental, Campinas, v.13, n.2, p.121-128, 2007.

CARDOSO, A. I. I., COSTA, C. P. Produção de bulbinhos de cebola em bandejas de isopor. Scientia Agricola, Piracicaba, v.56, n.4, p.969-974, 1999.

FERREIRA, D. F. SISVAR, Versão 4.6 (Build 6.0) DEX/FLA. 2003. Disponível em: http://www.dex.ufla.br/danielff/prog.htm . Acesso em: 05/11/2005.

JUNQUEIRA, A. H., PEETZ, M. S. Las exportaciones brasileñas de flores y plantas ornamentales crecen más del $124 \%$ entre 2001 y 2006. Horticultura Internacional, Tarragona, n.56, p.76-78, 2007.

LAKSO, A. N., REISH, B. I., MONTENSEN, J., ROBERTS, M. H. Carbon dioxide enrichment for stimulation of growth of in vitro-propagated grapevines after transfer from culture. Journal of the American Society for Horticultural Science, Alexandria, v.111, n.4, p.634-638, 1986.

LESKOVAR, D. I. Root and shoot modification by irrigation. HortTechnology, Alexandria, v.8, p.510-514, 1998.

MENEZES JÚNIOR, F. O. G., FERNANDES, H. S., MAUCH, C. R., SILVA, J. B. Caracterização de diferentes substratos e seu desempenho na produção de mudas de alface em ambiente protegido. Horticultura Brasileira, Brasília, v.18, n.3, p.164-170, 2000.

NESMITH, D. S., DUVAL, J. R. The effect of container size. HortTechnology, Alexandria, v.8, n.4, 495-498, 1998.
OLIVEIRA, J. P. de, COSTA, F. H. da S., PEREIRA, J. E. S. Crescimento de mudas micropropagadas de bananeira aclimatizadas nas condições da Amazônia sul ocidental sob a influência de diferentes substratos e recipientes. Revista Brasileira de Fruticultura, Jaboticabal, v.30, n.2, p.459-465, 2008.

OLIVEIRA, R. P., SCIVITTARO, W. B., VASCONCELLOS, L. A. B. C. Avaliação de mudas de maracujazeiro em função do substrato e do tipo de bandeja. Scientia Agricola, Piracicaba, v.50, n.2, p.261-266, 1993.

PARVIAINEN, J. V. Qualidade e avaliação de qualidade de mudas florestais. In: SEMINÁRIO DE SEMENTES E VIVEIROS FLORESTAIS, 1, Curitiba, 1981. Anais... Curitiba, FUPEF, 1981. p.59-90.

PEREIRA, P. R. G., MARTINEZ, H. E. P. Produção de mudas para o cultivo de hortaliças em solo e hidroponia. Informe Agropecuário, Belo Horizonte, v.20, n.200/201, p.24-31, 1999.

QUEIROZ, J. A. L. de, MALÉM JÚNIOR, N. J. Efeito do tamanho do recipiente sobre o desenvolvimento de mudas de açaí (Euterpe oleracea Mart.) Revista Brasileira de Fruticultura, Jaboticabal, v. 23, n.2, 2001.

REIS, G. G., REIS, M. G. F., MAESTRI, M. Crescimento de Eucalyptus camaldulensis, E. grandis e E. cloensiana sob diferentes níveis de restrição radicular. Revista Árvore, Viçosa, v.13, n.1, p.1-18, 1989.

SEABRA JÚNIOR, S., GADUM, J., CARDOSO, A. I. I. Produção de pepino em função da idade das mudas produzidas em recipientes com diferentes volumes de substrato. Horticultura Brasileira, Brasília, v.22, n.3, p.610-613, 2004.

SHEPHERD, K. R. Plantation silviculture. Dordrecht: Martinus Nijhoff, 1986. 322p.

SOUZA, E. R. B. de, CARNEIRO, I. F., NAVES, R. V., BORGES, J. D., LEANDRO, W. M., CHAVES, L. J. Emergência e crescimento de Cagaita (Eugenia dysenterica DC.) em função de tipos e volumes de substrato. Pesquisa Agropecuária Tropical, Goiânia, v.31, n.2, p.89-95, 2001.

SOUZA, P. V. D. Optimización de la produccion de plantones de cítricos en vivero: inoculación con mícorrizas vesiculares arbusculares. Valencia, Universidad Politécnica de Valencia, Valencia, 1995. 201p. Tesis (Doctoral). 